\title{
Foreword
}

\section{Vascular Anesthesia}

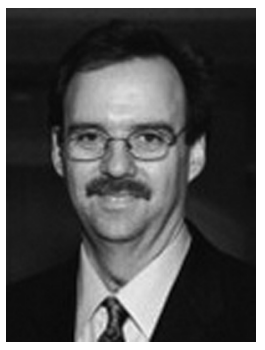

Lee A. Fleisher, MD

Consulting Editor

Given the prevalence of atherosclerosis, peripheral vascular disease continues to require surgical interventions. Despite numerous advances in interventional and less invasive techniques, many of these patients still require an anesthetic. In this issue of Anesthesiology Clinics, a group of experts in the care of these patients outlined management from the preoperative evaluation to postoperative care. In addition, there is an excellent article on surgical care, which is critical for providing optimal anesthesia for our patients.

In choosing a guest editor for this issue, I solicited Charles Hill, MD, Clinical Assistant Professor at Stanford University. Charles completed a residency in Anesthesiology at Vanderbilt University Medical Center and a Fellowship in Cardiovascular Anesthesiology at Stanford University Medical. He subsequently joined the faculty, where he is Medical Director of the Cardiovascular ICU. For this topic, he has brought together experts to help inform our practice.

Lee A. Fleisher, MD Perelman School of Medicine University of Pennsylvania Philadelphia, PA 19104, USA

E-mail address: lee.fleisher@uphs.upenn.edu 